\title{
An Improved Apparatus for the Determination of Liquidus Temperatures and Rates of Crystal Growth in Glasses ${ }^{1}$
}

\author{
By Oscar H. Grauer and Edgar H. Hamilton
}

\begin{abstract}
The liquidus temperature of a glass is the highest temperature at which equilibrium can coexist between the molten glass and the primary crystalline phase. An improved temperature-gradient apparatus is described for the rapid determination of liquidus temperatures and rates of erystal growth in glasses. In this method the use of small glass fragments confined in the cells of a platinum alloy holder largely eliminates the errors inherent in previous gradient methods. The procedure is simple and rapid. Liquidus temperatures in the range from $950^{\circ}$ to $1,225^{\circ} \mathrm{C}$ were determined to a precision of 4 degrees $\mathrm{C}$.

Rates of crystal growth were found to be linear. The usefulness to the glass technologist of data obtained by this method is indicated.
\end{abstract}

\section{Introduction}

Crystallization or devitrification is the most important limitation to the development of new glasses. The significance of this fact has been recognized by many investigators including Littleton $[1]^{2}$ in 1931 and Preston [2] in 1940, who emphasized the need for further study of devitrification in glass. Any such study must take into account two factors: (1) the liquidus temperature or maximum temperature at which equilibrium coexists between the glass and the primary crystalline phase; and (2) the rates of crystal growth at various temperatures. Such data are an important aid not only in the development of new glasses but also in the manufacturing processes of melting, forming, and annealing.

Most of the data that could be used in devitrification studies are expressed as phase equilibria diagrams, such as those compiled by Hall and Insley [3], which indicate the liquidus temperatures for various compositions but which present no information as to rates of crystal growth. The classical method for obtaining the liquidus temperature is the quenching method, which was used at the Geophysical Laboratory of the Carnegie Institution of Washington in phase studies of silicate systems. In this method a small powdered sample of glass or crystals, encased in a suitable container, usually a platinum foil envelope, is heated at a given temperature until equilibrium is attained and then quenched in air or some suitable liquid. The sample is examined with the petrographic microscope for crystals, and the process repeated at other temperatures until the highest temperature is found at which crystals persist.

In 1914 Tammann [4] determined the maximum rate of crystal growth of glass rods that had been heated in a known temperature gradient. Zschimmer and Dietzell [5] determined rates of crystal growth by placing a piece of glass on a platinum plate in a furnace and maintaining a given temperature for a specific time interval. After the sample was removed from the furnace, it was sectioned and the crystal size measured with a micrometer microscope. This procedure was repeated for each temperature at which data were desired, and from a graph of temperature and crystal size the temperature of maximum devitri-

\footnotetext{
${ }_{1}^{1}$ Presented at the meeting of the Glass Division of the American Ceramic Society, Bedford Springs, Pa., October 9, 1948.

2 Figures in brackets indicate the literature references at the end of this paper.
} 
fication was determined. Tabata [6] used a similar procedure to indicate relative rates of crystallization. Swift [7] used the same method with a modification for determining the rates of growth at temperatures immediately below the liquidus temperature. For these cases, the sample was placed over a small hole in a platinum foil, which permitted direct observation with a microscope after each heat treatment.

Parmelee and Monack [8] set up criteria for evaluating devitrification in glasses based on prescribed cooling cycles for small experimental melts.

A gradient method to determine liquidus temperature was developed by Silverman [9]. In this method a sample of powdered glass was placed in a platinum-alloy boat, which was inserted in a furnace in which a known temperature gradient was maintained. Preston [2] used the same method to determine both liquidus temperatures and rates of crystal growth.

In a previous investigation at this Bureau [10] the Silverman method was found to give good results except for those glasses that were very fluid at temperatures in the region of their liquidus temperatures. Such glasses had a tendency to flow when the boat was removed from the furnace, frequently resulting in erroneous values.

In the present investigation an improved apparatus has been developed that permits a rapid determination of liquidus temperatures and rates of crystal growth.

\section{Apparatus and Procedure}

The apparatus used for holding the glass sample is illustrated in figure 1 . It consisted of an inserted channel-shaped piece of platinum-10percent-rhodium alloy, $5 \frac{1}{2} \mathrm{in}$. long by $1 / 2 \mathrm{in}$. wide. Open cells for containing small fragments of glass were spaced along the length of the holder.

The cells were tapered from a 2 -mm-diameter opening at the top to a 1-mm-diameter opening at the bottom and extended $1 \mathrm{~mm}$ below the surface. At one end of the channel the cells were spaced in two parallel rows $3 / 16$ in. apart. In each of the parallel rows the cells were separated by $1 / 8$ in. from center to center, but since one row offset the other by $1 / 16$ in., the distance along the channel between centers of succeeding cells was $1 \frac{1}{16}$ in. This interval was found to correspond to a temperature difference of about $5 \mathrm{deg}$ C in the temperature gradient. At the other end of the apparatus the cells were spaced $1 / 4 \mathrm{in}$. apart between centers in a single row along the length of the strip, corresponding to a $20 \mathrm{deg} C$ temperature difference. In actual operation, the holder was so positioned in the temperature gradient that liquidus temperatures could be determined within the region of the closely spaced cells of the parallel rows and measurements of crystal sizes within the cells of the single row.

The horizontal tube furnace consisted of two concentric, spirally grooved alundum cores, insulated from each other and encased in a steelshell packed with diatomaceous earth. The inner core was wound with platinum-20-percentrhodium wire along a central zone for a distance of 6 in. and the outer core with a nickel-chromium alloy wire along $20 \mathrm{in}$. of its length.

A fairly linear temperature gradient was ob. tained by adjusting the current in both windings with small variable transformers. The maximum temperature of the furnace was maintained constant to within $\pm 2 \mathrm{deg}$. C by means of a commercial-type electronic controller operating from a platinum-platinum-10-percent-rhodium thermocouple located in the hot zone. As a result, a stable gradient was maintained in the remainder of the furnace.

Temperatures in the gradient were measured with a movable platinum-platinum-10-percentrhodium thermocouple in conjunction with a potentiometer. The thermocouple was encased by a double-bore clay insulating tube except for the last half inch at the hot junction.

In making liquidus temperature determinations and measurements of rates of crystal growth in glass, the following procedure was used. A small piece of glass or of glass-crystal mixture, about 1 $\mathrm{cm}$ in each dimension, was crushed in a hardenedsteel mortar, and the fragments were transferred to a sheet of black paper or black glass to facilitate the selection of particles of the desired size. Pieces about $2 \mathrm{~mm}$ long and $1 \mathrm{~mm}$ wide were loaded into the cells of the platinum holder, which was then inserted and positioned accurately in the furnace. The sample holder was left in the gradient furnace for the desired time, usually 20 to $60 \mathrm{~min}$. for experimental glasses. A temperature probe at $1 / 2$-in. intervals was then made of the gradient with the movable thermocouple, and the 



C

Figure 1. Platinum alloy specimen holder.

a, Photograph of holder; b, line drawing, plan view; c, section through $\mathrm{A}-\mathrm{A}$ of view (b) showing position in furnace in relation to inner furnace tube and movable thermocouple.

holder was removed immediately (air-quenched) from the furnace by means of a long wire hook.

Since the cells confined the glass, no displacement due to flow occurred when the holder was removed rapidly from the furnace. Surface tension prevented the glass from flowing out of the lower opening. After air quenching, the holder was placed on the microscope stage, and the contents of the cells were examined with a petrographic microscope. The opening in the bottom of each cell permitted direct examination of the enclosed sample using transmitted light, thereby obviating the necessity of breaking away the glass from the holder. The last cell that contained crystals was considered to locate the position in the temperature gradient corresponding to the liquidus temperature. The temperature of the cell was obtained by linear interpolation between the two nearest points of the temperature probe.

In general, each fragment of glass tended to take the shape of the platinum cell when the temperature was above the softening point and to assume a somewhat lenticular appearance. For photomicrography it was desirable to avoid the optical distortion and uneven illumination due to the curved surfaces. This was effected by placing cover glasses at both surfaces of the sample and interposing a drop or two of a liquid having the same index of refraction as the glass sample. A cover glass with an appropriate liquid sufficed for the visual measurement of crystal sizes.

In determining the crystal size, Preston's 
method of making measurements of the semimajor axis of the crystal or of the radius of spherulitic crystals was used. Corrections were made for the foreshortening effect of those crystals that did not lie in the plane perpendicular to the optical axis of the microscope. A microscope, containing a filar micrometer eyepiece, was focussed sharply on one end of the crystal or of the radius of the spherulite. The crosshair was brought into coincidence with the image, and the readings of the micrometer and the microscope fine adjustment scale were noted; the microscope was refocussed on the other end of the crystal or on the radiant point of the spherulite; the crosshair was repositioned; the new readings of both scales were observed. The horizontal projection of the crystal or of the radius was obtained from the difference of the micrometer scale readings, and the vertical projection from the product of the difference of the microscope scale readings and the index of refraction of the glass. From these data the true size of the crystal was determined by the geometrical relationship as indicated in figure 2. An average of four measurements of different spherulites was used for the data. The reproducibility of the measurements was about 2 percent.

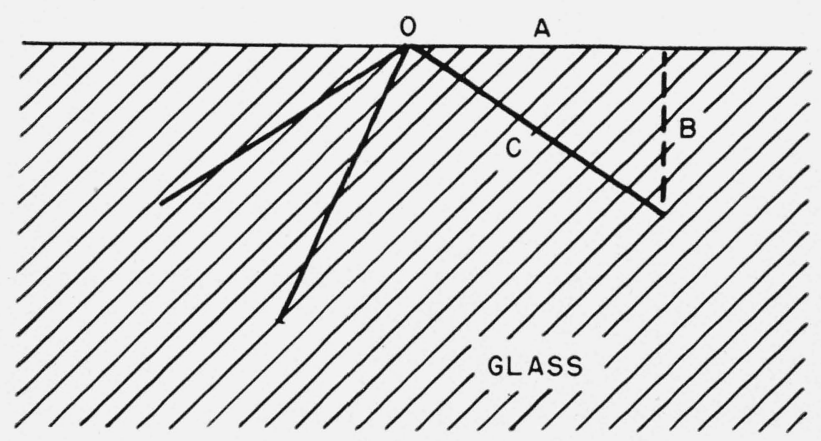

Figure 2. Geometrical solution of spherulitic radii.

The radius $C$ is determined by the equation $C=\sqrt{A^{2}+(B N)^{2}}$, where $A$ is the horizontal projection, $B$ is the vertical projection, and $N$ is the index of refraction of the glass.

Measurements by Preston [2] indicated that the rate of crystal growth in glass was linear with time only during the first stages. A more recent investigation by Swift [7] showed that the rate of crystal growth in glass was constant until the crystallization zones from opposite surfaces met. In the present investigation the linearity of crystal growth was also observed from measurements made on various types of glasses.
Thus, both the rates of crystal growth at various temperatures and the liquidus temperature could be obtained after only one treatment. However, in those cases where the rate of crystal growth was very rapid, a short treatment of 5 or $10 \mathrm{~min}$ was desirable so that the crystals in the region of maximum devitrification would not interfere with each other and depart from linearity in their rates of growth. In these few instances a separate determination was made of the liquidus temperature.

\section{Results and Discussion}

\section{Liquidus Temperature Determinations}

Liquidus temperature determinations were made for five different glasses using the classical quenching method, the Silverman method, and the new method. The results are listed in table 1 and the compositions of the glasses in table 2. The values of duplicate determinations with the new method show less scatter than those with the Silverman method. Considering the values obtained by the quenching method as the standards for comparison, the average deviation of the values obtained by the new method is $3.6 \mathrm{deg} \mathrm{C}$ as compared to $7.2 \mathrm{deg} \mathrm{C}$ for the Silverman method. The greatest deviation between duplicate determinations for the new method was $6 \mathrm{deg} \mathrm{C}$ compared to $23.4 \mathrm{deg} \mathrm{C}$ for the Silverman method.

TABLE 1. Liquidus temperature determinations

\begin{tabular}{|c|c|c|c|c|c|c|c|c|}
\hline \multirow[t]{2}{*}{ Glass } & \multirow{2}{*}{$\begin{array}{c}\begin{array}{c}\text { Classical } \\
\text { quench- } \\
\text { ing } \\
\text { method }\end{array} \\
{ }^{\circ} \mathrm{C}\end{array}$} & \multicolumn{4}{|c|}{ Silverman method } & \multicolumn{3}{|c|}{ New method } \\
\hline & & ${ }^{\circ} \mathrm{C}$ & ${ }^{\circ} \mathrm{C}$ & ${ }^{\circ} \mathrm{C}$ & ${ }^{\circ} C(A v g)$ & ${ }^{\circ} \mathrm{C}$ & ${ }^{\circ} \mathrm{C}$ & ${ }^{\circ} C(A v g)$ \\
\hline E $1105 \ldots$ & 958.5 & 960 & 954 & - n & 957 & 957 & 953 & 955 \\
\hline E $994 \ldots$ & $1,011.0$ & 1,001 & 1,010 & - & 1,006 & 1,017 & 1,017 & 1,017 \\
\hline E $1067 \ldots$ & $1,079.0$ & 1,072 & 1,078 & $\ldots$ & 1,075 & 1,074 & 1,079 & 1,076 \\
\hline E $955 \ldots$ & $1,170.0$ & 1,159 & 1,167 & 1,167 & 1,164 & 1,165 & 1,172 & 1,168 \\
\hline E 1055 & $1,223.4$ & 1,200 & 1,209 & $-\ldots$ & 1,204 & 1,218 & 1,221 & 1,220 \\
\hline
\end{tabular}

TABLE 2. Compositions a

\begin{tabular}{|c|c|c|c|c|c|c|c|c|c|c|}
\hline Glass & $\mathrm{SiO}_{2}$ & $\mathrm{~B}_{2} \mathrm{O}_{3}$ & $\mathrm{BaO}$ & $\mathrm{BeO}$ & $\mathrm{CaO}$ & $\mathrm{La}_{2} \mathrm{O}_{3}$ & $\mathrm{Na}_{2} \mathrm{O}$ & $\mathrm{Al}_{2} \mathrm{O}_{3}$ & $\mathrm{Ta}_{2} \mathrm{O}_{5}$ & $\mathrm{ZnO}$ \\
\hline & $w t \%$ & $w t \%$ & $w t \%$ & $w t \%$ & $w t \%$ & $w t \%$ & $w t \%$ & $w t \%$ & $w t \%$ & $w t \%$ \\
\hline E $1105 \ldots$ & 70.00 & ..... & ...... & ...... & 10.0 & ...... & 20.0 & .... & & \\
\hline E $994 \ldots$ & 23.2 & 17.0 & 54.2 & 2. 2 & & & & 3.4 & & \\
\hline E $1067 \ldots$ & 14.0 & 16. 2 & 33.1 & 1. 2 & & 24.4 & & & 11.1 & \\
\hline E $955 \ldots$ & 14.6 & 16.9 & 31.9 & 1.3 & & 33.9 & & $\ldots$ & & 1.4 \\
\hline E $1055 \ldots$ & 12. 7 & 16.5 & 33.8 & 1.3 & & 33.1 & & 2.6 & & 10 \\
\hline
\end{tabular}

\& All compositions calculated from batch proportions. 
It is among the glasses that are very fluid at their liquidus temperatures that the results obtained by the Silverman method are erratic, due to the flow of the molten glass in the boat upon removal from the furnace.

In the new method flow is practically eliminated by confining the specimens to the small cells of the holder. Due to the small mass of the sample and its intimate thermal contact with the platinum alloy cell, equilibrium is more quickly attained, and cooling of the sample on removal approaches the quenching method in its rapidity.

\section{Rates of Crystal Growth}

Figure 3 gives the values of crystal size and temperature for glass E 1105, for heat treatments of 13,26 , and $60 \mathrm{~min}$. It indicates that the maximum size for each holding period occurs at about the same temperature, $895^{\circ} \mathrm{C}$. Up to $1 \mathrm{hr}$ the rates of crystal growth (at a given temperature),

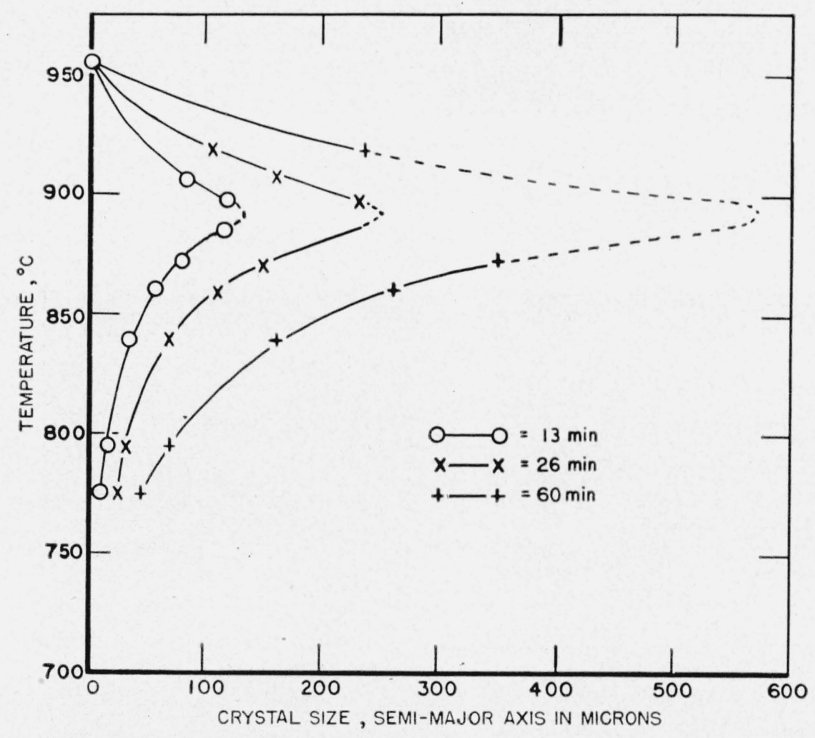

Figure 3. Effect of temperature on crystal size for treatments of 13, 26 , and $60 \mathrm{~min}$.

which are the slopes of the curves in fig. 4, were found to be linear. When rates of crystal growth are plotted against temperature, the curve in fig. 5 is obtained. In this curve the rate of crystal growth is zero at the liquidus temperature, and the maximum rate occurs at about $895^{\circ} \mathrm{C}$. Figures 6 and 7 are photomicrographs of devitrite crystals that were grown in glass E 1105 $\left(\mathrm{Na}_{2} \mathrm{O}, 20 \% ; \mathrm{CaO}, 10 \% ; \mathrm{SiO}_{2}, 70 \%\right)$ at $860^{\circ} \mathrm{C}$ for 13 and $26 \mathrm{~min}$, respectively.

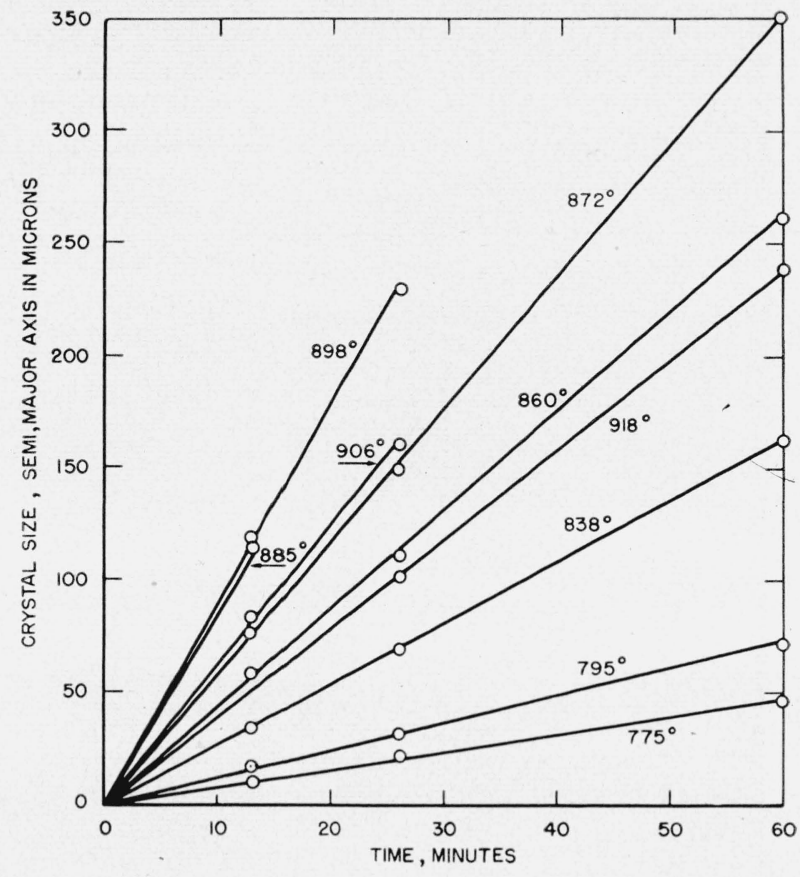

Figure 4. Effect of duration of treatment at constant temperature on crystal size.

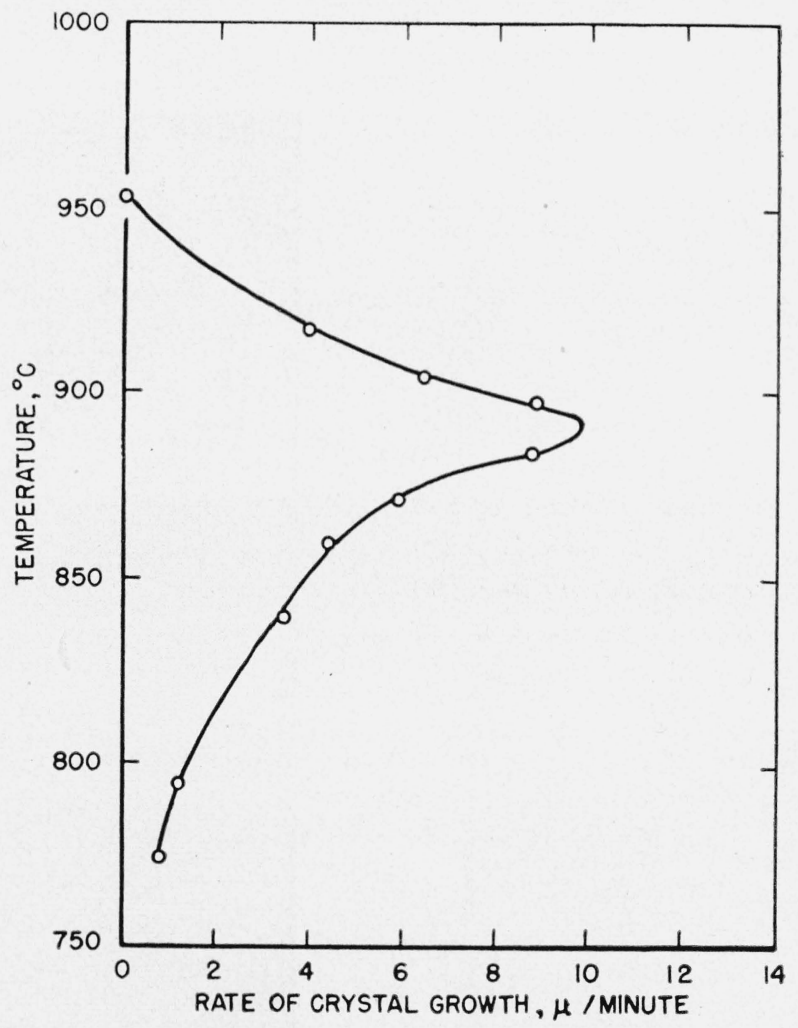

FIGURE 5. Rate of crystal growth versus temperature. 


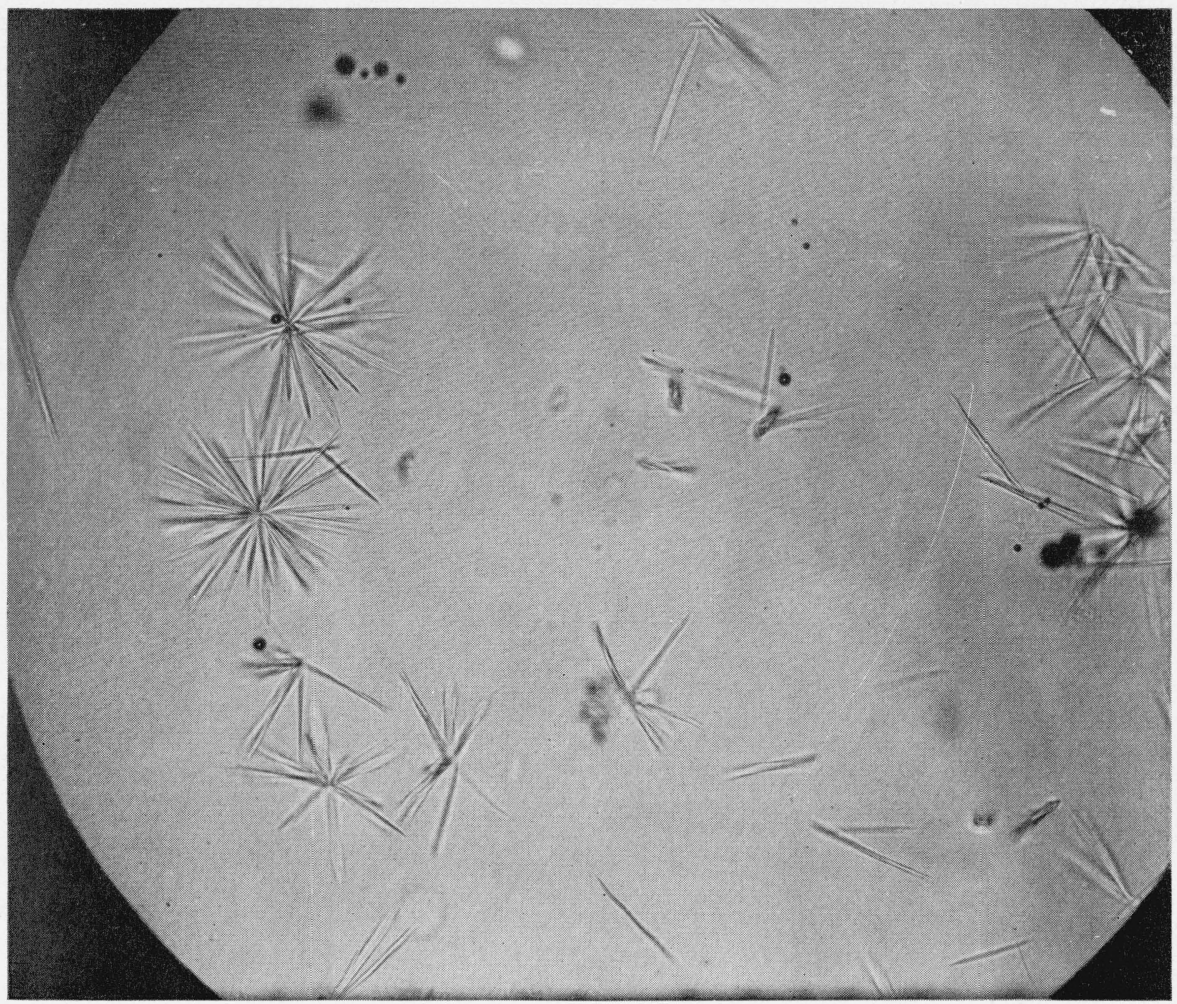

Figure 6. Photomicrograph of devitrite crystals $\times 200$ after 13 min treatment at $860 C$.

Figure 7. Photomicrograph of devitrite crystals $\times 200$ after 26 min treatment at $860^{\circ} \mathrm{C}$, focus at center of crystals.

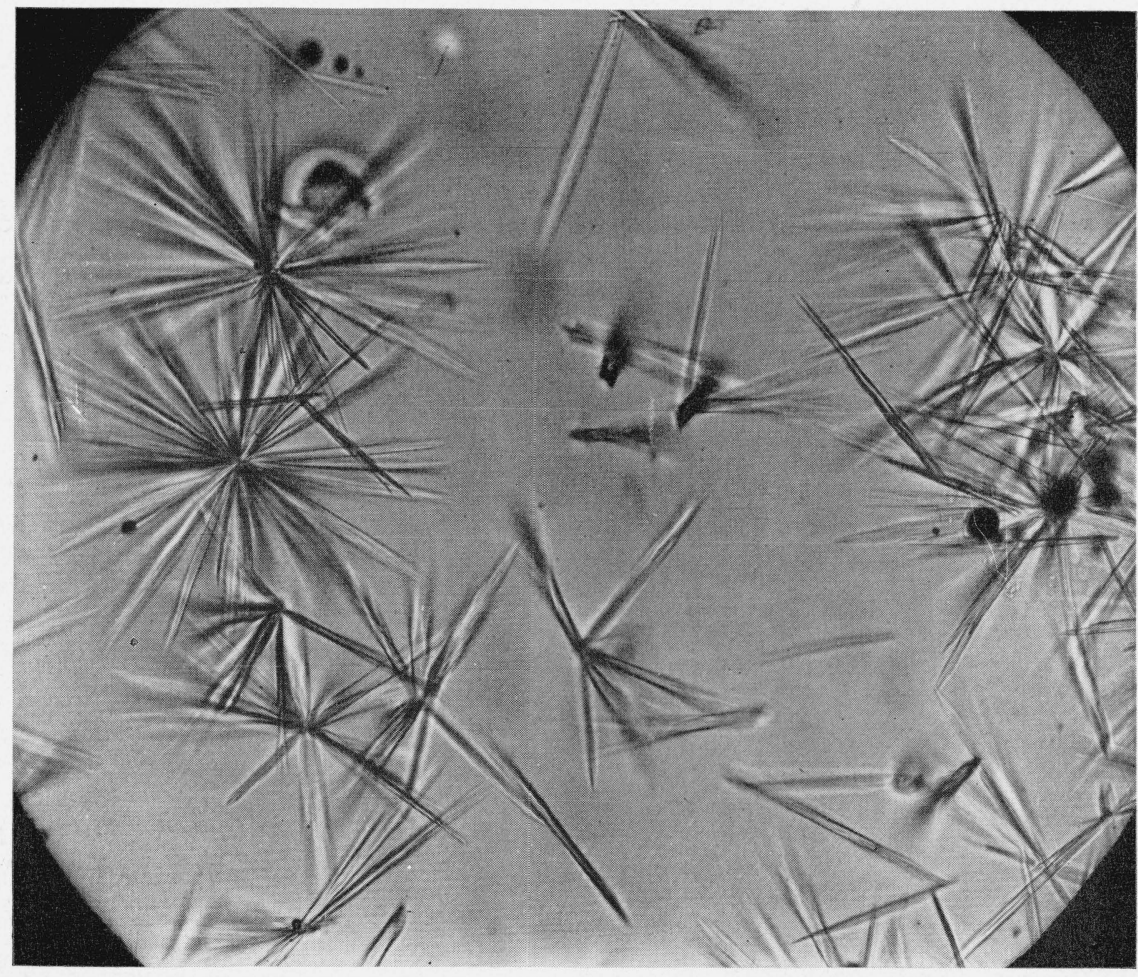


Figure 8. Photomicrograph of same devitrite crystals as figure 7 with microscope focused at ends of crystals.

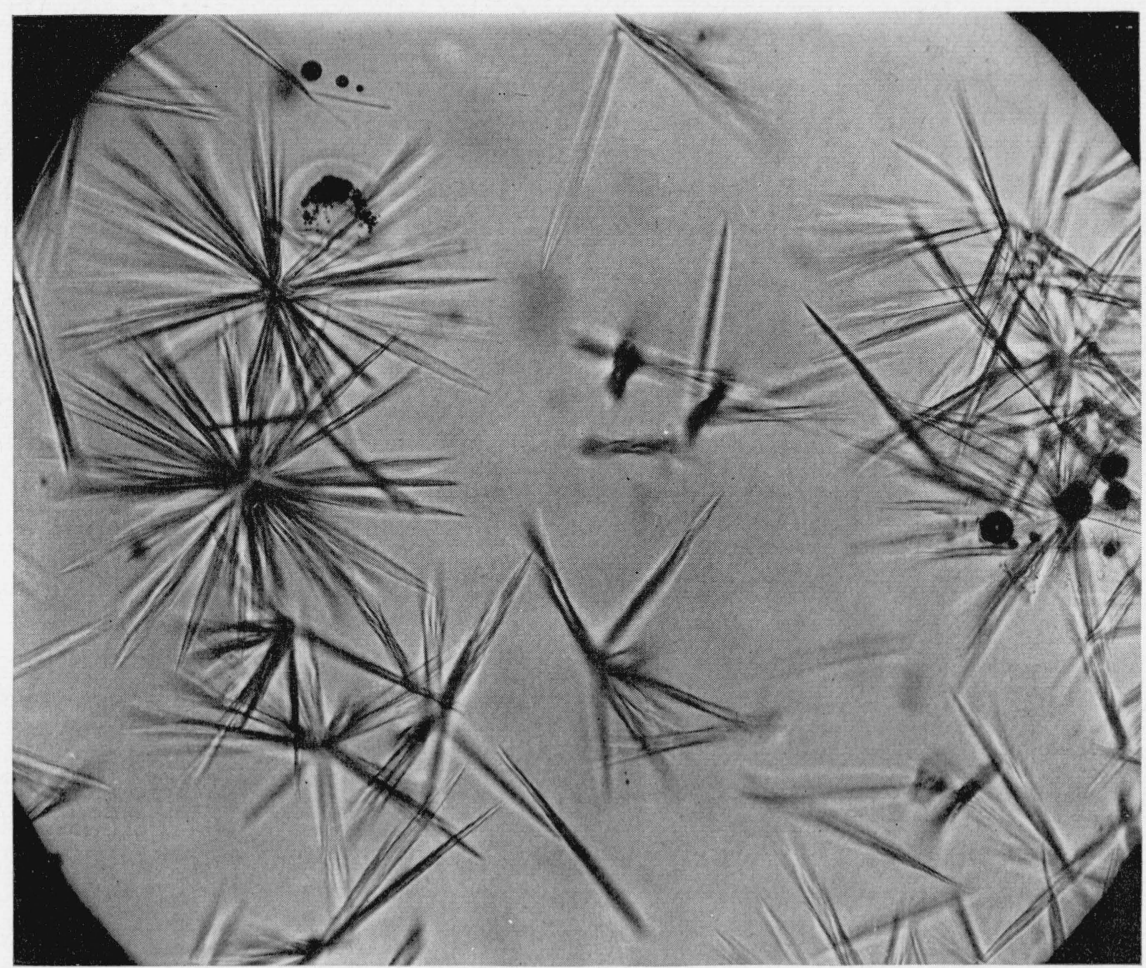

The photomicrograph shown in figure 7 was obtained with the microscope focused on the centers of the spherulites. It can be seen that the end of the spherulites are out of focus, indicating varying degrees of inclination. The photomicrograph shown in figure 8 was obtained when some of the ends of the same spherulites had been brought into focus; this time the centers are out of focus. Values of maximum rates of crystal growth for two glasses are given in table 3. Other determinations of crystal growth as an indicator

TABLE 3. Rates of crystal growth for glass forming and nonglass-forming materials

\begin{tabular}{|c|c|c|}
\hline Material & $\begin{array}{c}\text { Maximum rate } \\
\text { of crystal } \\
\text { growth }\end{array}$ & $\begin{array}{c}\text { Tem- } \\
\text { pera- } \\
\text { ture }\end{array}$ \\
\hline & $\mu /$ min & ${ }^{\circ} \mathrm{C}$ \\
Glass E 1105_..... & 9.8 & 895 \\
Glass E 1222 \& (devitri- & 63.3 & 890 \\
fies readily). & & \\
Picric acid b (nonglass- \\
forming). & 860,000 & 85 \\
Phosphorus ${ }^{\circ}$ (non- & $60,000,000$ & $\mathrm{~d} 25$ \\
\hline glass-forming). & & \\
\hline
\end{tabular}

a A low-dispersion, high-index experimental glass.

b A. Bogojawlensky, Z. physik. Chem. 27, 585 (1898).

- M. D. Gernez, Compt. rend. 95, 1278 (1882).

d Not maximum. of devitrification have been made with this apparatus. From these results, suitable time-temperature schedules have been derived for the slumping of large interferometer plates and other large disks of various types of optical glasses without the usual devitrification.

\section{Viscosity and Crystal Growth}

Various attempts $[7,11,12,13,14]$ have been made to find a relationship between the rate of crystal growth and the temperature. Below the liquidus temperature, the stable state of a system consists of crystals or a mixture of glass and crystals. The glassy phase at ordinary temperatures is unstable; even at a temperature below the softening point of the glass, the viscosity may be sufficiently low so that crystals may grow at a measurable rate.

In reviewing the kinetics of crystallization, the familiar hump-shaped curve of rate of crystal growth and temperature can be considered as the result of two opposing forces: a driving force that increases as we depart from the liquidus temperature and a resisting force related to the viscosity, which increases exponentially and plays the dominant role as the temperature is diminished. The 
rate of crystal growth has been shown to be inversely proportional to the viscosity: by Frenkel [11] on the basis of the classical activation theory, by Richards [12] using the concept of thermal relaxation time, and by Leontjewa [13], empirically in a series of $\mathrm{Na}_{2} \mathrm{O}-\mathrm{SiO}_{2}$ glasses. The latter used the equation,

$$
v=K / \eta+K_{0} \log \eta,
$$

where $v$ is linear speed of crystallization, $\eta$ is the viscosity, and $K$ and $K_{0}$ are constants, $K_{0}$ being very small.

Swift [9] used the semiempirical equation of Preston,

$$
R=K \frac{\left(T_{\mathrm{liq}}-T\right)}{\eta}
$$

where $R$ is the rate of crystal growth, $T_{11 q}$ is the liquidus temperature, $T$ is the temperature during holding period, $\eta$ is the viscosity, and $K$ is a constant. A plot of this equation fitted one set of his data fairly well but not others.

From a consideration of the difference in vibrational energy between condensation and melting at a plane glass-crystal boundary, Cox and Kirby [14] derived an equation for the rate of crystal growth of the form,

$$
R=A^{-E_{1} / K T} 1-(r+1)^{E_{1}-E_{2}},
$$

where $E_{1}$ is the vibrational energy needed to make the ions in the glass mobile, $E_{2}$ the energy that is necessary to make the ions in the crystal mobile, $r$ the ratio of the surface densities of crystal and glass, $T$ the absolute temperature, and $A$ and $K$ are constants. While this equation gave a fair fit for most of their data, there was poor agreement at temperatures immediately below the liquidus temperature for the two borosilicate-type glasses that they used.

A comparison of the rates of crystal growth in glass-forming and nonglass-forming materials (table 3) shows the tremendous differences in their rates of growth. As the rate of crystal growth increases it becomes increasingly difficult to produce glass.

\section{Summary}

An improved apparatus for the rapid determination of liquidus temperatures and rates of crystal growth has been developed.

The simplified technique required with this apparatus makes it possible for an inexperienced operator to determine quickly data that formerly required much time and skill.

A rapid means is provided the glass technologist for assessing the effects of changes in composition upon the devitrification characteristics of glasses.

The authors express thanks to William $\mathrm{R}$. Eubank for his aid in determining liquidus temperatures by the quenching method, to Charles P. Saylor for aid in preparing the photomicrographs, and to Clarence H. Hahner for helpful suggestions.

\section{References}

[1] J. L. Littleton, J. Soc. Glass Tech. Trans. 15, 262 (1931).

[2] E. Preston, J. Soc. Glass Tech. 24, 139 (1940).

[3] F. P. Hall and H. Insley, J. Am. Ceram. Soc. 30, No. 11, part 2 (1947).

[4] G. Tammann, J. Soc. Glass Tech. 9, 166 (1925).

[5] E. Zschimmer and A. Dietzel, Sprechsaal 60, 110, 129, 165, 186, 204 (1927).

[6] K. Tabata, Researches Electrotechnical Laboratory, Japan, No. 191 (1927).

[7] H. R. Swift, J. Am. Ceram. Soc. 30, 165 (1947).

[8] C. W. Parmelee and A. J. Monack, J. Soc. Glass Tech. 13, 322 (1929).

[9] W. B. Silverman, J. Am. Ceram. Soc. 22, 378 (1939).

[10] E. H. Hamilton, O. H. Grauer, Z. Zabowsky, and C. H. Hahner, J. Research NBS 40, 361 (1948) RP1881.

[11] J. Frenkel, Physik. Z. Sowjetunion 1, 498 (1932).

[12] W. T. Richards, J. Chem. Phys. 4, 449 (1936).

[13] A. A. Leontjewa, Acta Physicochim. URSS, 14, 245 (1941).

[14] S. M. Cox and P. L. Kirby, Nature 159 [4031] 162 (1947).

Washington, February 13, 1950. 